\title{
ASSESSMENT OF ANXIETY AND DEPRESSION AMONG PATIENTS IN A GOVERNMENT TEACHING GENERAL HOSPITAL
}

\author{
Usha Rani Chadalawada1, Sudha Kumari P2, Sandhya Rani M³, Aruna Devi $S^{4}$ \\ 1 Professor, Department of Community Medicine, Government Siddhartha Medical College, Vijayawada. \\ ${ }^{2}$ Associate Professor, Department of Community Medicine, Guntur Medical College. \\ ${ }^{3}$ Postgraduate, Department of Community Medicine, Government Siddhartha Medical College, Vijayawada. \\ 4 Postgraduate, Department of Community Medicine, Government Siddhartha Medical College, Vijayawada.
}

ABSTRACT
AIM AND OBJECTIVES
To assess the level of anxiety and depression among patients admitted into Government Teaching General Hospital, in one of
the South Indian teaching institutions.

\section{BACKGROUND}

Depression is a common illness worldwide with an estimated 350 million people affected. Depression is different from usual mood fluctuations and short-lived emotional responses to challenges in everyday life. Especially when long-lasting and with moderate or severe intensity, depression may become a serious health condition. It can cause the affected person to suffer greatly and function poorly at work, at school and in the family. At its worst, depression can lead to suicide. Over 800,000 people die due to suicide every year. Suicide is the second leading cause of death in 15-29 year olds. The burden of depression and other mental health conditions is on the rise globally. A World Health Assembly resolution passed in May 2013 has called for a comprehensive, coordinated response to mental disorders at country level. In India, the suicide rate was 10.8 in 2008 and in the last three decades (1975-2008), the rate has gone up by 43\%.[1]

In southern states, the rate is more than 15 per 1 lakh, while in North India the rate is 3 per 1 lakh. This variable pattern has been stable for last 20 years.

\section{METHODS}

Design: Hospital-based cross-sectional study. Setting: Medical College Hospital, Govt. Medical College, Hospital, Andhra Pradesh. HADS questionnaire was used to assess the anxiety and depression among the patients admitted into hospital.

\section{RESULTS}

353 patients were interviewed. Depression was more common than anxiety (38.6\% Vs. 31.3\%). There is no significant association between literacy status, different age groups. Prevalence of anxiety and depression was more common in the lower socio-economic groups than upper class, which was significant.

\section{CONCLUSION}

Prevalence of anxiety and depression was high in a hospital setting. This study highlights the importance of the simultaneous evaluation and management of anxiety and depression in hospitalized patients.

\section{KEYWORDS}

Mental Illness, Anxiety, Depression.

HOW TO CITE THIS ARTICLE: Chadalawada UR, Kumari SP, Rani SM, et al. Assessment of anxiety and depression among patients in a government teaching general hospital. J. Evolution Med. Dent. Sci. 2016;5(64):4528-4531, DOI: 10.14260/jemds/2016/1034

\section{INTRODUCTION}

The stresses of medical illness and hospitalization are numerous and significant. Depression causes disability of life and has negative effects on the body's recovery from illness.[2] The mental stresses of medical illness and hospitalization are both very high and add to the morbidity of the existing ill health. Apart from medical illness, the hospital environment itself can be stressful as it separates patients from usual environment and social support.[3] Unrecognised and untreated depression has major implications in compliance

Financial or Other, Competing Interest: None.

Submission 20-03-2016, Peer Review 29-04-2016,

Acceptance 02-05-2016, Published 10-08-2016.

Corresponding Author:

Dr. Usha Rani Chadalawada,

Professor, Department of Community Medicine,

Government Siddhartha Medical College,

Vijayawada-520008.

E-mail: dr.usha1@gmail.com

DOI: $10.14260 /$ jemds/2016/1034 to medical treatment and may increase the frequency of consultation with health services. ${ }^{[4]}$ A study showed the prevalence of anxiety and depression in hospitalized medical patients is high, occurs mainly in women and no relation to illness perception are associated with both illness perception of greater severity and less improvement. [5]

The prevalence of depression and anxiety amounting to around $50 \%$ in patients with chronic obstructive pulmonary disease and depression in hospitalized patients with congestive heart failure was high. In a study done in hospitalized patients in internal and surgical wards in Iran, anxiety was detected in $50.4 \%$ of patients and depression in $53.6 \%$ of them.[6] Similar such studies found on literature search showed that 350 million people suffer from depression and this is a common illness worldwide. Anxiety is a common problem that is present in over $40 \%$ of the patients and their attendants that access the hospital services. 
When long-lasting and with moderate or severe intensity, depression and anxiety may become a serious health condition. This also calls for integrating mental health into primary care with the observation that it has become public health problem as well. This has prompted us to understand the magnitude of the problem in the current teaching hospital in order to customize the health care services in this hospital setting.

The objective of this study was to study the prevalence of anxiety and depression in hospitalized patients in a tertiary care setting by using HADS questionnaire and to see whether there is any significant association of various sociodemographic variables with anxiety and depression levels in study subjects.

\section{MATERIALS AND METHODS}

The study was designed as a hospital-based cross-sectional study. Data collection was carried out for a period of two months, i.e. October to November 2014 in a medical college hospital of inpatients. Ethical clearance from the Institute Ethical Committee was obtained before the conduction of the study. Data was collected from the patients who were admitted into the hospital from medical and surgical wards. All those who are willing and over $50 \%$ of patient population consented to participate and give their consent in written form were included in this study. However, patients who are under the age of 18 years and above the age of 65 years were excluded from the study as our focus was on only productive age group who will cater to the needs of the extreme age groups. A validated measurement tool, the Hospital Anxiety and Depression Scale (HADS) developed by Zigmond and Snaith was used in this study to collect data.[7] Each symptom is scored as per Likert scale from $0-3$, that 0 indicating no such symptom and 3 indicating the greatest possible scores of the anxiety or depression subscales can range from 0-21. Subjects who rate more than 10 on the anxiety or depression subscale are considered to be probable cases of anxiety and depression (Case); a rating that falls between eight and ten are considered to be possible cases (Borderline); and ratings less than 8 are considered to be normal. Data then collected was entered into Microsoft Excel Sheet. Statistical analysis included the chi square test, and $\mathrm{p}$ values $<0.05$ were considered statistically significant.

\section{RESULTS}

Hospital anxiety and depression scale was assessed in 353 consecutive patients with mean age of 35.3 years ( $S D=12.789)$. Out of total 353 study subjects, males were 190 $(53.8 \%)$ and $163(46.2 \%)$ were females. It is seen that most of the patients were educated and only $30.28 \%$ were with no education. A total of 169 patients (47.8\%) were from surgical wards (ENT, Surgery, Orthopaedics, OBG), whereas 184 $(52.2 \%)$ were from medical wards.

\begin{tabular}{|c|c|c|c|}
\hline Level of Anxiety/Depression & Male & Female & \\
\hline \multicolumn{4}{|c|}{ Anxiety } \\
\hline Normal (0-7 score) & $132(69.5)$ & $111(68.1)$ & \multirow{3}{*}{$\begin{array}{c}X 2=0.08 \\
d . F=2 \\
P=0.78\end{array}$} \\
\hline Borderline (8-10) & $33(17.5)$ & $28(17.2)$ & \\
\hline Possible (11-21) & $25(13)$ & $24(14.7)$ & \\
\hline \multicolumn{4}{|c|}{ Depression } \\
\hline Normal (0-7 score) & $116(61)$ & $102(62.5)$ & \multirow{3}{*}{$\begin{array}{c}X 2=0.08 ; \\
d . F=2 \\
P=0.78\end{array}$} \\
\hline Borderline $(8-10)$ & $37(19.5)$ & $31(19)$ & \\
\hline Possible (11-21) & $37(19.5)$ & $30(18.5)$ & \\
\hline Total & 190 & 163 & \\
\hline
\end{tabular}

Borderline anxiety was found in $34.7 \%$ of the patients and $27.7 \%$ were possible cases. Borderline depression was found in $38.5 \%$ of patients and $38 \%$ were possible cases. Overall depression was more in the patients than anxiety $(38.24 \%$ vs
$31.2 \%)$. It is also observed in our study that anxiety and depression was almost equal in both males and female patients. The difference observed is also not significant [Table 1].

\begin{tabular}{|c|c|c|c|c|c|}
\hline Age Groups & $<25$ yrs. & $25-40$ yrs. & 40-55 yrs. & $>55$ yrs. & \\
\hline \multicolumn{6}{|c|}{ Anxiety } \\
\hline Normal & $51(65.3)$ & $76(73.7)$ & $69(66.9)$ & $47(68.1)$ & \multirow{3}{*}{$\begin{array}{c}\mathrm{X} 2=1.69 \\
\text { d. } \mathrm{F}=6 \\
\mathrm{P}=0.6171\end{array}$} \\
\hline Borderline & $13(16.7)$ & $16(15.5)$ & $20(19.4)$ & $12(17.4)$ & \\
\hline Probable & $14(17.4)$ & $11(10.7)$ & $14(13.6)$ & $10(14.6)$ & \\
\hline \multicolumn{6}{|c|}{ Depression } \\
\hline Normal & $46(58.9)$ & $73(70.8)$ & $62(60.9)$ & $37(53.6)$ & \multirow{3}{*}{$\begin{array}{c}X 2=5.92 \\
\text { d.F }=6 \\
P=0.1156\end{array}$} \\
\hline Borderline & $18(23.1)$ & $16(15.5)$ & $20(19.4)$ & $14(20.2)$ & \\
\hline Probable & $14(18.0)$ & $14(13.6)$ & $21(20.3)$ & $18(26.1)$ & \\
\hline Total & 78 & 103 & 103 & 69 & \\
\hline
\end{tabular}

It is observed that anxiety was more in the patients less than 25 years of age and after 40 years of age. However, the depression was more common after the age of 55 years. It is also seen that middle aged patients were more stable. The difference observed between the level of anxiety, depression and age groups were statistically not significant [Table 2]. 
It was observed that patients with no education or higher educational levels were less anxious than with minimal education, but the difference observed was statistically not significant $\left[\mathrm{X}^{2}=0.7882, \mathrm{p}>0.05\right]$.

Depression was more among the [patients with patients without any education] than with some education and the difference observed was statistically not significant $\left[X^{2}=4.12\right.$, $\mathrm{p}>0.05$ ].

A clear socio-economic gradient is observed in our study. Prevalence of anxiety and depression was significantly more in patients who were belonging to lower class than middle and upper class. $(\mathrm{p}<0.05)$ as Modified Kuppuswamy's Socioeconomic Scale with newer Income Criteria of 2012.

\begin{tabular}{|c|c|c|c|c|}
\hline & Illiterate & Schooling & College & \\
\hline \multicolumn{5}{|c|}{ Anxiety } \\
\hline Normal & $77(70.4)$ & $81(65.8)$ & $85(70.2)$ & \multirow{3}{*}{$\begin{array}{c}\mathrm{X} 2=0.7882 \\
\mathrm{df}=4 \\
\mathrm{P}=0.6743\end{array}$} \\
\hline Borderline & $19(16.4)$ & $24(19.5)$ & $18(14.9)$ & \\
\hline \multirow[t]{2}{*}{ Probable } & $13(10.9)$ & $18(14.6)$ & $18(14.9)$ & \\
\hline & 109 & 123 & 121 & \\
\hline \multicolumn{5}{|c|}{ Depression } \\
\hline Normal & $59(54.2)$ & $82(66.7)$ & 77 (63.6) & \multirow{3}{*}{$\begin{array}{c}X 2=4.12 \\
\text { d.F }=4 \\
P=0.127\end{array}$} \\
\hline Borderline & 27 (24.7) & $18(14.6)$ & $23(19.0)$ & \\
\hline Probable & 23 (21.1) & 23 (18.9) & $21(17.4)$ & \\
\hline Total & 109 & 123 & 121 & \\
\hline \multicolumn{5}{|c|}{$\begin{array}{c}\text { Table 3: Association Between the Literacy Status } \\
\text { and Anxiety and Depression Levels }\end{array}$} \\
\hline
\end{tabular}

\section{DISCUSSION}

In this study, there is higher proportion of males than females and it is in accordance to other studies. This study also shows that the prevalence of anxiety and depression was more than the expected lifetime prevalence for anxiety in the community, but it was consistent with other studies.[2,8] In our study, the depression was more common finding in uneducated patients than anxiety which was more common in the patients with some education and the similar findings were observed by Tabassumali et al.[9] A study conducted by Ana Lopez-de-Andrés et al[10] in Spain on prevalence of depression in hospitalized patients with diabetes from 2001 to 2011 showed that older age and greater comorbidity were significantly associated with a higher risk of dying among diabetic patients with concomitant depression and also the study showed that the prevalence of depression increased significantly among hospitalized diabetic patients from 2001 to 2011 even if the health profile has improved over this period.

A study conducted by Daniela Singh.[11] On 140 hospitalized patients in Punjab showed that mean of depression among male hospitalized patients 63.51 and female hospitalized patients 74.68. The difference between the two mean was highly significant $(' \mathrm{t} '=9.45, \mathrm{df}=138, \mathrm{P}<0.01$ ) and it concluded that the female hospitalized patients had significantly high depression than the male hospitalized patients. Catalano $\mathrm{G}$ and et al[12] studied the Anxiety and Depression in hospitalized patients in Resistant Organism Isolation. He conducted this study to assess whether there is an increase in symptoms of Isolation and Depression in patients who are not critically ill and are placed in isolation. Patients hospitalized with methicillin-resistant staphylococcus aureus or vancomycin-resistant Enterococcus species infections were evaluated with the Hamilton Anxiety Rating Scale and the Hamilton Depression Rating Scale at baseline and again during hospitalization.

The results were then compared with the results of patients who were hospitalized for infectious diseases that did not require isolation. Patients in isolation had significantly higher scores on both the anxiety and depression scales at the time of follow-up than did patients who were not isolated. There was no significant difference between the scores of the two groups before isolation. The results of this preliminary study suggest that placement in resistant organism isolation may increase hospitalized patients' levels of anxiety and depression. A study done on anxiety and depression in patients with gastrointestinal cancer using HADS score by Azadeh Tavoli et al[13] at Tehran Cancer Institute showed that the mean anxiety score was 7.6 $(\mathrm{SD}=4.5)$ and for the depression this was $8.4 \quad(\mathrm{SD}=3.8)$. Overall, $47.2 \%$ and $57 \%$ of patients scored high on both anxiety and depression.

There were no significant differences between gender, educational level, marital status, cancer site and anxiety and depression scores, whereas those who knew their diagnosis showed a significant higher degree of psychological distress [mean (SD) anxiety score: knew diagnosis 9.1 (4.2) vs. 6.3 (4.4) did not know diagnosis, $\mathrm{P}<0.001$; mean (SD) depression score: knew diagnosis 9.1 (4.1) vs. 7.9 (3.6) did not know diagnosis, $\mathrm{P}=0.05]$. Performing logistic regression analysis while controlling for demographic and clinical variables studied the results indicated that those who knew their cancer diagnosis showed a significant higher risk of anxiety [OR: 2.7, 95\% CI: 1.1-6.8] and depression [OR: 2.8, 95\% CI: 1.1-7.2], which indicates that the cultural issues and the way we provide information for patients play important role in their improved or decreased psychological well-being.

\section{CONCLUSION}

The prevalence of anxiety and depression is very high in the hospital setting. It is also important that we regularly screen for patients attending to the hospital early on as one-fourth of the patients coming for general complaints do have subclinical anxiety and depression either one or the other or two of them together. It is also important to sensitize health care personnel to look for suggestive signs of the disease to be able to provide needed care.

The data on this problem is inadequate, hence need to be trained social workers and counsellors to be documented from hospitals and communities to enable them to seek treatment. Thus, there is need for creating awareness among population by way of health education and look for warning signs of mental ill-health. There is not enough data on this problem of anxiety and depression in patients in particular and population in general. Hence, there is a need to create awareness and sensitization of the health personnel. That is training the medico-social workers and counsellors to help in the management of the disease from early diagnosis and 
facilitate comply with treatment with the patient. They also help in seeking treatment early amongst the other family members of the patient and the respective communities that they come from.

Hence, we recommend that it is necessary to have a regular counsellor in order to counsel the patients and it is also essential to screen all the patients for psychological comorbidities at the time of clinical interview.

\section{REFERENCES}

1. WHO Depression, http://www.who.int/mediacentre/factsheets/fs369/en/.

2. Hadi N, Jamali N, Rahimi E. The prevalence of anxiety and depression in adult hospitalization patients in internal and surgical wards of Shiraj hospitals. Shiraj E Medical journal 2010;11(3):137-47.

3. Mark SG, Philip RM. Psychological responses to illness. In the American psychiatric publishing text book of Psychosomatic medicine. New York Mc Grew Hill publishers 2006;3rd ed:67-87.

4. Yohannes AM, Baldwin RC, Connouy J. Depression and anxiety in elderly patients with chronic obstructive pulmonary disease. Age and aging 2006;35(5):457-9.

5. Victor IR, Mood Disordrs. In: Howard HG, editor. Review of general psychiatry. Baltimore, Maryland 2000;301-14.

6. Mikkelsen RL, Middleboe T, Pisinger C, et al. Anxiety and depression in patients with chronic obstructive pulmonary disease (COPD). A review Nord J Psychiatry 2004;58(1):65-70.
7. Zigmond AS, Snaith RP. The hospital anxiety and depression scale. Acta Psychiatr Scand 1983;67(6): 36170.

8. Khan N, Malik MA. Presentation of burn injuries and their management outcome. J Pak Med Assoc 2006;56(9): 3947.

9. Tabassum Alvi, Fatima Assad, Aurangazeb, et al. Anxiety and depression in burn patients. J Ayub Med coll Abbottabad 2009;21(1):137-41.

10. Ana Lopez-De-Andrés, Jiménez-Trujillo MI, HernándezBarrera V, et al. Trends in the prevalence of depression in hospitalized patients with type 2 diabetes in Spain: analysis of hospital discharge data from 2001 to 2011. PLoS One 2015;10(2):e0117346. doi: 10.1371/journal.pone.0117346.

11. Daniela Singh. A study frustration, depression and anxiety of hospitalized patients. Indian Streams Research Journal ISSN 2230-7850, 2015;5(9).

12. Catalano G, Houston SH, Catalano MC, et al. Anxiety and depression in hospitalized patients in resistant organism isolation. South Med J search that 2003;96(2):141-5.

13. Azadeh Tavoli, Mohagheghi MA, Montazeri A, et al. Anxiety and depression in patients with gastrointestinal cancer: does knowledge of cancer diagnosis matter? BMC Gastroenterol 2007;7:28. 